Journal of Agricultural Sciences
(Tarim Bilimleri Dergisi)

\title{
Determining the Most Stable Potato Genotypes Using AMMI Yield Stability Analysis Method
}

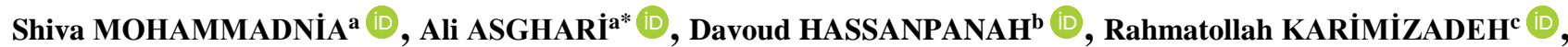 \\ Ali Akbar SHOKOUHIANd ${ }^{\text {(D) }}$ \\ ${ }^{a}$ University of Mohaghegh Ardabili, Faculty of Agriculture and Natural Resources, Department of Agronomy and Plant Breeding, Ardabil, IRAN

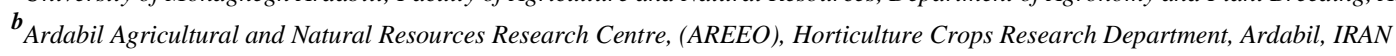 \\ ${ }^{c}$ Dryland Agricultural Research Institute (DARI), Agricultural Research, Education and Extension Organization (AREEO), Gachsaran, IRAN

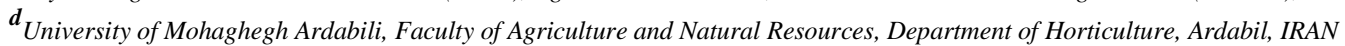

ARTICLE INFO

Research Article

Corresponding Author: Ali ASGHARI, E-mail: ali_asgharii@yahoo.com

Received: 10 June 2019 / Revised: 14 December 2019 / Accepted: 15 December 2019 / Online: 31 May 2021

\section{ABSTRACT}

Genotype-environment interaction (GEI) is very important for breeders. It is considered a complicated issue in breeding programs to obtain stable and high-yielding genotypes to release new genotypes. This study was conducted to achieve a stable high-yielding genotype that is adaptive to climatic conditions of potato-producing regions in Iran. A total of 20 potato breeding lines along with five commercial varieties (Savalan, Agria, Caesar, Luta and Satina) were evaluated in a randomized complete block design with three replicates in the Agricultural Research and Natural Resources Stations of five location (Ardabil, Razavi Khorasan, Karaj, Isfahan and Hamadan) in Iran, for two years (2016 and 2017). Combined ANOVA of yield data for studied genotypes and environments indicates significant differences among potato genotypes, environments, and GE interaction was significant. Thus, the AMMI method and its parameters were used to analyze yield stability. The results indicated that only four interaction principal components were significant $(\mathrm{P}<0.01)$, which accounted for $81.2 \%$ of the GEI sum of squares. Based on type 1 parameters $\left(\mathrm{SIPC}_{1}, \mathrm{FA}_{1}, \mathrm{Za}_{1}, \mathrm{Dz}_{1}, \mathrm{EV}_{1}\right.$, and $\left.\mathrm{Da}_{1}\right)$, genotypes $\mathrm{G} 7, \mathrm{G} 10$, G14, G20 and G24 were identified as to be stable. Moreover, according to the results of type 2, 3 and 4 parameters, genotypes G2, G6, G7, G14, G15 and G20, as well as cultivars Agria (G24) and Luta (G23), were found to be stable. Genotypes G6, G7, G14, G15, G20, and G24 were stable according to the ASV parameter, and genotypes G6 and G7 were stable based on the MASV parameter. Amongst the stable genotypes identified by the AMMI parameters, while genotype G6 was highyielding, G14 and G24 (Agria) were moderate-yielding.

Keywords: AMMI Parameters, Potato Genotypes, Stability, Tuber Yield

(C) Ankara University, Faculty of Agriculture

\section{Introduction}

Potato (Solanum tuberosum L.) is the fourth staple food after wheat, rice, and corn in terms of nutrition and production importance (Fufa 2013). Given the growing rate of population and its consequences, such as hungrier people and more demand for food, the Food and Agricultural Organization (FAO) has introduced potato as a food security plant (Devauxet et al. 2014). Thus, the need for expanding potato production is globally felt to manage the increase in food demands and food security (Hassanabadi et al. 2013). Achievement to high-yield, adaptive, and stable genotypes is one of the main goals of potato breeders. However, Genotype-environment interaction (GEI) renders breeding programs difficult and complex (Kadhem \& Baktash 2016). GEI is a genotype's response to environmental changes (Crossa et al. 1991). It is important to understand the GEI structure and nature in breeding programs because a significant GEI can restrict efforts to select superior genotypes when introducing new varieties and cultivars in breeding programs (Shafii \& Price 1998). Numerous statistical methods have been proposed to study GEI to determine stable genotypes (Sabaghnia et al. 2008). These methods can be divided into two categories-univariate and multivariate (Karimizadeh et al. 2012).

Among the multivariate methods, the additive main effect and multiplicative interaction (AMMI) model is more credible and widely used (Byarugaba et al. 2018). The AMMI model was first used by Gauch (1988) to analyze yield data. Then, Gauch and Zobel (1988) fully expanded and analyzed this model. In plant breeding, this method affects the accuracy of genotype yield estimation in multi-environment trials. Such an accurate estimation is obtained through evaluation and prediction via dissociating the data into modeling and validation data as well as comparing the values expected from the model with validation data (Safavi \& Bahraminejad 2017). The AMMI is an integrated model of analysis of variance (ANOVA) and principal component analysis. This model first calculates the main effect of genotypes and environments using the ANOVA methods, and then, the genotype and environmental components of the interaction are computed for the matrix of deviation from incremental effect (Crossa et al. 
1990). The first part of the AMMI model, the summable part, uses usual variance analysis, while the second part is multiplicative and utilizes the method of interaction principal component analysis to dissociate GEI into a range of 1 to $n$ principal components (Omrani et al. 2018). It is noteworthy to mention that in the AMMI method, the calculations are performed on the values of GEI, while the computation of principal components is performed on the differentials of main data from the total mean of entire data (Gauch 1988). The estimation accuracy of the AMMI method is similar to increasing the number of replicates. This method can be used to reduce replicates and related expenses, which, in turn, allows the use of more treatments to the experiment (Crossa et al. 1991).

Tarakanovas and Ruzgas (2006) introduced AMMI as an effective method to study GEI and stated that its bi-plots could determine the suitable varieties for cultivation in various environments as well as the varieties for cultivation in certain environmental conditions. The AMMI method is widely used to evaluate GEI and has been employed by various researchers for the selection of stable genotypes of potato (Byarugaba et al. 2018), sunflower (Khomari et al. 2016), oats (Safavi \& Bahraminejad 2017), durum wheat (Karimizadeh et al. 2016), canola (Pourdad \& Jamshid Moghaddam 2013) and lentil (Sabaghnia et al. 2008). Worku et al. (2018) used the multivariate method and index of the AMMI stability value and concluded that the clone CIP396004.337 possessed the highest yield and stability. In a study conducted by Byarugaba et al. (2018) on 21 Dutch potato varieties from 2015 to 2016 in five regions, they utilized the multivariate methods, including the AMMI, and suggested eight varieties for the Uganda region.

To investigate the stability based on the AMMI model, various parameters have been proposed, such as Euclidean distance from the origin of significant Interaction Principal Component (IPC) axes (Da) (Annicchiarico 1997), distance of Interaction Principal Component (IPC) point with origin in space (Dz) (Zhang et al. 1998), absolute value of the relative contribution of IPCs to the interaction (Za) (Zali et al. 2012), stability statistic based on the first IPC axes in the fitted AMMI model (FA) (Raju 2002). Zobel (1994) introduced a parameter, i.e., averages of square eigenvector values (EV). Alternatively, another parameter, i.e., sums of the absolute value of the IPC scores (SIPC), was propounded by Sneller et al. (1997). Based on the two first Interaction Principal Component Analysis (IPCAs), AMMI stability value (ASV) (Purchase 1997) and modified AMMI stability value (MASV) (Zali et al. 2012) have been proposed.

The present study aims to identify and select stable high-yielding genotypes for potato-producing regions in Iran using the AMMI model and its parameters.

\section{Material and Methods}

\subsection{Plant material and treatments}

In this study, 20 potato genotypes (Table 1) and five standard varieties (Savalan, Agria, Caesar, Luta, and Satina) were evaluated in five locations (Ardabil, Razavi Khorasan, Karaj, Isfahan, and Hamadan) in Iran in two years (2016-2017). The climatic conditions and geographic location of the studied areas are presented in Table 2. The experimental design in all locations was randomized complete block with three replicates in both years. The chemical fertilizers, including ammonium phosphate, urea, and potassium sulfate whose dosages were calculated by the soil test, were incorporated into the soil (Table 3 ). All breeding lines and control varieties were cultivated in two six-meter-long rows with inter-row spacing of $75 \mathrm{~cm}$ and inter-plant spacing of $25 \mathrm{~cm}$. Colorado beetles were controlled by applying $250 \mathrm{~mL} \mathrm{ha}^{-1}$ Imidacloprid (Confidor). The plots were weeded in two stages within a 10- to 15-centimeter distance from the plants. The genotype yields were measured after the harvest.

Table 1-The list of the potato breeding lines and standard cultivars studied in this research

\begin{tabular}{|c|c|c|c|c|c|c|c|c|c|}
\hline \multirow{2}{*}{$N O$} & \multirow{2}{*}{ Line cod } & \multicolumn{2}{|c|}{ Parents } & \multirow{2}{*}{$N O$} & \multirow{2}{*}{ Line cod } & \multicolumn{2}{|c|}{ Parents } & \multirow{2}{*}{$N O$} & \multirow{2}{*}{$\begin{array}{c}\text { Standard } \\
\text { cultivars }\end{array}$} \\
\hline & & q & $\lambda$ & & & q & $\hat{0}$ & & \\
\hline G1 & 16 & Luta & Caesar & G11 & 3 & Luta & Caesar & G13 & Caesar \\
\hline G2 & 9 & Luta & Caesar & G12 & 2 & Luta & Caesar & G22 & Satina \\
\hline G3 & 15 & Luta & Caesar & G14 & 21 & Luta & Savalan & G23 & Luta \\
\hline G4 & 11 & Luta & Caesar & G15 & 5 & Luta & Savalan & G24 & Agria \\
\hline G5 & 13 & Luta & Caesar & G16 & 1 & Luta & Savalan & G25 & Savalan \\
\hline G6 & 5 & Luta & Caesar & G17 & 2 & Luta & Savalan & & \\
\hline G7 & 23 & Luta & Caesar & G18 & 3 & Luta & Savalan & & \\
\hline G8 & 56 & Luta & Caesar & G19 & 16 & Luta & Savalan & & \\
\hline G9 & 12 & Luta & Caesar & G20 & 14 & Luta & Savalan & & \\
\hline G10 & 4 & Luta & Caesar & G21 & 13 & Luta & Savalan & & \\
\hline
\end{tabular}


Table 2- Climatic conditions and geographical position of studied regions

\begin{tabular}{|c|c|c|c|c|c|c|c|c|}
\hline \multirow{2}{*}{ Location } & \multirow{2}{*}{ Latitude } & \multirow{2}{*}{ Longitude } & \multirow{2}{*}{$\begin{array}{l}\text { Altitude } \\
\text { (m) }\end{array}$} & \multicolumn{3}{|c|}{ Temperature $\left({ }^{0} \mathrm{C}\right)$} & \multirow{2}{*}{$\begin{array}{l}\text { Precipitation } \\
\quad(\mathrm{mm})\end{array}$} & \multirow{2}{*}{$\begin{array}{c}\text { Relative } \\
\text { humidity (\%) }\end{array}$} \\
\hline & & & & Average & Minimum & Махітит & & \\
\hline Ardabil & $48^{\circ} 18^{\prime} \mathrm{E}$ & $38^{\circ} 15^{\prime} \mathrm{N}$ & 1351 & 9.90 & 4.10 & 15.80 & 277 & 68 \\
\hline Hamedan & $48^{\circ} 32^{\prime} \mathrm{E}$ & $34^{\circ} 48^{\prime} \mathrm{N}$ & 1550 & 11.35 & 3.93 & 18.77 & 384 & 53 \\
\hline Karaj & $51^{\circ} 00^{\prime} \mathrm{E}$ & $35^{\circ} 48^{\prime} \mathrm{N}$ & 1312 & 14.40 & 8.00 & 20.80 & 247 & 53 \\
\hline Razavi Khorasan & $59^{\circ} 23^{\prime} \mathrm{E}$ & $35^{\circ} 34^{\prime} \mathrm{N}$ & 1600 & 14.10 & 7.10 & 21.10 & 225 & 55 \\
\hline Esfahan & $51^{\circ} 40^{\prime} \mathrm{E}$ & $32^{\circ} 37^{\prime} \mathrm{N}$ & 1550 & 16.25 & 9.10 & 23.40 & 123 & 40 \\
\hline
\end{tabular}

Table 3- Planting date and harvest of potato genotypes and Chemical fertilizers consumption in studied locations

\begin{tabular}{lccccc}
\hline \multirow{2}{*}{$\begin{array}{l}\text { Location } \\
\text { Planting } \\
\text { dates }\end{array}$} & $\begin{array}{c}\text { Harvest } \\
\text { dates }\end{array}$ & $\begin{array}{c}\text { Ammonium phosphate } \\
\left(\mathrm{kg} \mathrm{ha}^{-1}\right)\end{array}$ & $\begin{array}{c}\text { Urea } \\
\left(\mathrm{kg} \mathrm{ha}^{-1}\right)\end{array}$ & $\begin{array}{c}\text { Potassium sulfate } \\
\left(\mathrm{kg} \mathrm{ha}^{-1}\right)\end{array}$ \\
\hline Ardabil & 25-30 April & 2-15 October & 150 & 300 & 100 \\
Hamedan & 15-20 June & 16-21 November & 100 & 250 & 150 \\
Karaj & 25-30 June & 19-21November & 150 & 300 & 100 \\
Razavi Khorasan & 10-15 June & 18-22 October & 100 & 350 & 200 \\
Esfahan & 5-10 June & 17-20 October & 150 & 350 & 150 \\
\hline
\end{tabular}

\subsection{Statistical analysis}

To determine the stability of the genotypes, the multivariate AMMI model whose statistical model is as follows was utilized:

$Y_{I J}=\mu+g_{i}+e_{j}+\sum_{n=1}^{N} \lambda_{n} \gamma_{i n} \delta_{j n}+\rho_{i j}$

Where; $Y_{i j}$, denotes the yield of $i$ th genotype in $j$ th environment; $\mu$, is the grand mean; $g_{i}$ and $e_{j}$, are the genotype and the environment deviations from the grand mean, respectively; $\lambda_{n}$, is the eigenvalue of the $n$th principal component axis; $\gamma_{i n}$ and $\delta_{j n}$, are the eigenvectors of the genotype and environment for the axis $n$, respectively; and $\rho_{i j}$, is the error term.

Several statistics of the AMMI model were employed to investigate the stability of the genotypes. Various parameters, including EV (Zobel 1994), SIPC (Sneller et al. 1997), Da (Annicchiarico 1997), Za (Zali et al. 2012), and FA (Raju 2002) were also calculated. Furthermore, the first tow IPCA was used for computing ASV (Purchase 1997) and MASV (Zali et al. 2012).

$$
\begin{aligned}
& Z a i=\sum_{n=1}^{N}\left|\gamma_{i n} \partial_{n}\right| \\
& D Z i=\sqrt{\sum_{n=1}^{N} \gamma_{i n}^{2}} \\
& M A S V=\sqrt{\sum_{K=1}^{N-1}\left(S S I P C_{n} / S S I P C_{n+1}\right)(I P C n)^{2}+(I P C n+1)^{2}} \\
& A S V=\sqrt{(\mathrm{SSIP} 1 / \mathrm{SSIP} 2)(\mathrm{IPC} 1)^{2}+(\mathrm{IPC} 2)^{2}} \\
& D a i=\sqrt{\sum_{\mathrm{n}=1}^{\mathrm{N}}\left(\lambda_{\mathrm{n}} \gamma_{\mathrm{in}}\right)^{2}} \\
& E V=\sum_{\mathrm{n}=1}^{\mathrm{N}} \gamma_{\mathrm{in}}^{2} / \mathrm{n} \\
& S I P C=\sum_{\mathrm{n}=1}^{\mathrm{N}} \lambda_{\mathrm{n}}^{0.5} \gamma_{\mathrm{in}} \\
& F A=\sum_{n=1}^{N} \lambda_{n}^{2} \gamma_{i n}^{2}
\end{aligned}
$$

To draw the bi-plot, Minitab 16 software was used, and the entire analyses and calculations of the AMMI model were carried out with of Genstat Release 12.0. 


\section{Results and Discussion}

The results of the combined analysis of variance of yield data showed that the effects of environment (each location and year was considered as different environment), genotype, and their interactions were significant $(\mathrm{P}<0.01$; Table 4$)$. The effect of genotype, environment, and GEI accounted for 7.2\%, 35.5\%, and $42.3 \%$ of the total sums of squares, respectively. The mean

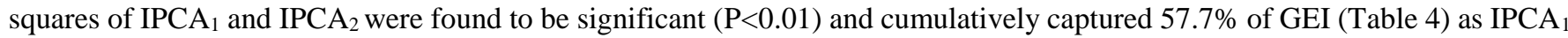
and IPCA $\mathrm{A}_{2}$ components accounted for $34 \%$ and $23.7 \%$ of GEI sum of the squares, respectively. The IPCA 3 and IPCA explained $_{4}$ $13.1 \%$ and $10.4 \%$ of the GEI variations, respectively. In total, the first four components accounted for $81.2 \%$ of the GEI variation. Thus, the remaining components of the model cover only $18.2 \%$ of the sum squares of GEI.

Table 4- Combined analysis of yield data of potato genotypes (lines and standard cultivars)

\begin{tabular}{lrrrll}
\hline Source & \multicolumn{1}{c}{$d f$} & \multicolumn{1}{c}{ SS } & \multicolumn{1}{c}{$M S$} & Proportion & Noise \\
\hline Environments & 9 & 27981 & $68.51^{* *}$ & $0.355 \mathrm{a}$ & $0.007^{\mathrm{c}}$ \\
Genotypes & 24 & 5676 & $10.33^{* *}$ & $0.072 \mathrm{a}$ & $0.097^{\mathrm{c}}$ \\
Genotype $\times$ Environment & 216 & 33347 & $154.4^{* *}$ & $0.423 \mathrm{a}$ & $0.148^{\mathrm{c}}$ \\
IPCA 1 & 32 & 11334 & $354.2^{* *}$ & $0.340 \mathrm{~b}$ & - \\
IPCA 2 & 30 & 7893 & $263.1^{* *}$ & $0.237 \mathrm{~b}$ & - \\
IPCA 3 & 28 & 4390 & $156.8^{* *}$ & $0.131 \mathrm{~b}$ & - \\
IPCA 4 & 26 & 3477 & $133.7^{* *}$ & $0.104 \mathrm{~b}$ & - \\
Residuals & 100 & 6252 & 62.5 & - & $0.423^{\mathrm{d}}$ \\
Error & 480 & 10984 & 22.9 & - & - \\
Total & 749 & 78896 & 105.3 & - & - \\
\hline
\end{tabular}

$*$ and **, significant at 0.05 and 0.01 respectively; IPCA, Interaction Principal Component Analysis; ${ }^{\text {a }}$, Calculated by dividing on sum of (GEN, ENV, and GEN $\times$ ENV) SS; ${ }^{\text {, }}$ Calculated by dividing on ENV $\times$ GEN interaction SS; ${ }^{c}$, Calculated by [(df $\times$ MS Error $\left.) / \mathrm{SS}\right]$; ${ }^{\text {, }}$ The portion of residual SS from total $\mathrm{GEN} \times \mathrm{ENV}$ was calculated as SSE/(ENV $\times$ GEN SS)

To better understand the AMMI model, a bi-plot (Figure 1) was drawn. Genotypes G5, G9, G12, G15, G16, G17, G18, G21, and G23 (cv. Luta) and environments E2, E9 and E5 were found to have higher IPCA1 and, hence, the highest interactions. In Figure 1, the vertical line in the mid-section of the bi-plot indicates the grand mean value of the two experimental years. The genotypes and environments on the right had higher yields than mean. As the bi-plot illustrates, genotypes G1, G3, G5, G6, G8, G9, G17, G19, and G25 (cv. Savalan) possessed the highest mean yield. Among the environments, E1, E2, and E9 had the highest yield, while E3 had the lowest (Table 5).

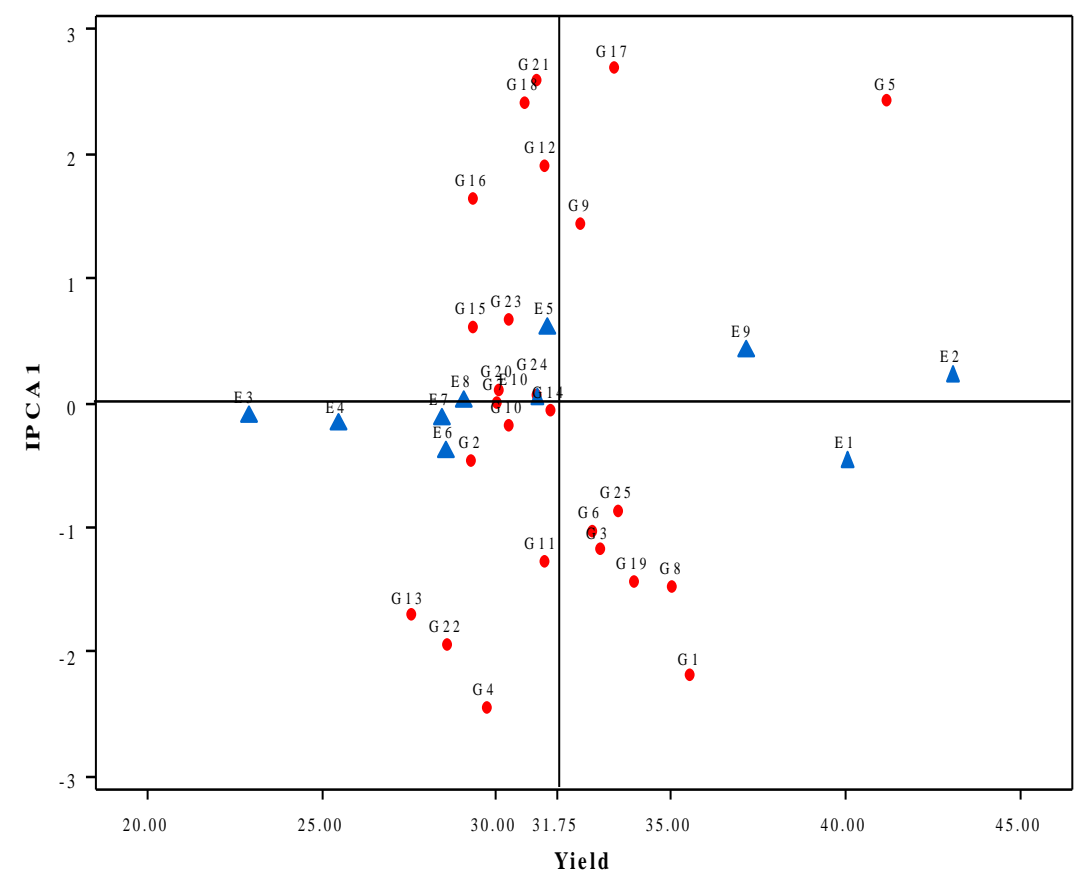

Figure 1- The bi-plot of mean yield and first principle component for potato genotypes and 10 environments 
Table 5- The mean yield and interaction principle components (IPCAs) of yield for all environments

\begin{tabular}{lccccc}
\hline Environment & $\begin{array}{c}\text { Environment } \\
\text { Code }\end{array}$ & Yield $\left(t \mathrm{ha}^{-1}\right)$ & IPCA1 & IPCA2 & IPCA3 \\
\hline Ardabil (2016) & E1 & 40.07 & -3.677 & -0.086 & -2.61 \\
Hamedan (2016) & E2 & 43.05 & 1.701 & -5.278 & 0.761 \\
Karaj (2016) & E3 & 22.88 & -0.909 & 1.762 & 4.107 \\
Isfahan (2016) & E4 & 25.45 & -1.411 & 1.296 & -0.272 \\
Razavi Khorasan (2016) & E5 & 31.44 & 4.626 & 3.144 & -1.497 \\
Ardabil (2017) & E6 & 28.55 & -3.05 & -1.11 & -1.027 \\
Hamedan (2017) & E7 & 28.44 & -0.98 & 2.385 & -0.266 \\
Karaj (2017) & E8 & 29.05 & 0.133 & -0.795 & -0.526 \\
Isfahan (2017) & E9 & 37.12 & 3.23 & -1.024 & -1.509 \\
Razavi Khorasan (2017) & E10 & 31.16 & 0.337 & -0.301 & 2.833 \\
\hline
\end{tabular}

To evaluate the stability of the genotypes and environments and to associate the genotypes to the various environments, another bi-plot was utilized (Figure 2). Figure 2 illustrates the bi-plot using IPCA1 and IPCA2 for studied genotypes and environments. Accordingly, stable genotypes can be introduced and various environments can be classified. The genotypes and environments in the center of the bi-plot, i.e., environments E3, E4, E7, E8, and E10 along with genotypes G7, G14, G20 and G24 (cv. Agria) had the minimum genotype $\times$ environment interaction. So, they were superior to the other genotypes and environments in terms of not having GEI. The genotypes adjacent to an environment were specifically adaptive to the related environment and the genotypes near the component axes were found to have more general adaptation. Therefore, genotypes G14 and G24 (cv. Agria) were specifically adapted to environments E10; genotypes G15 and G23 (cv. Luta) were specifically adapted to environment E5; and genotypes G7 and G20 were specifically adapted to environments E1, E3, and E6 (Figure 2). On the other hand, genotypes G6, G7, G10, G14, G16, G20, G21, G24 (cv. Agria), and G13 (cv. Caesar) exhibited general adaptation because they were closer to the axes of the principal components of the interactions (Figure 2). Since 57.5 percent of the variance - i.e. more than half of the entire variance - was captured by the first and second principal components, it was better to use the results of the AMMI model's statistics to determine stability.

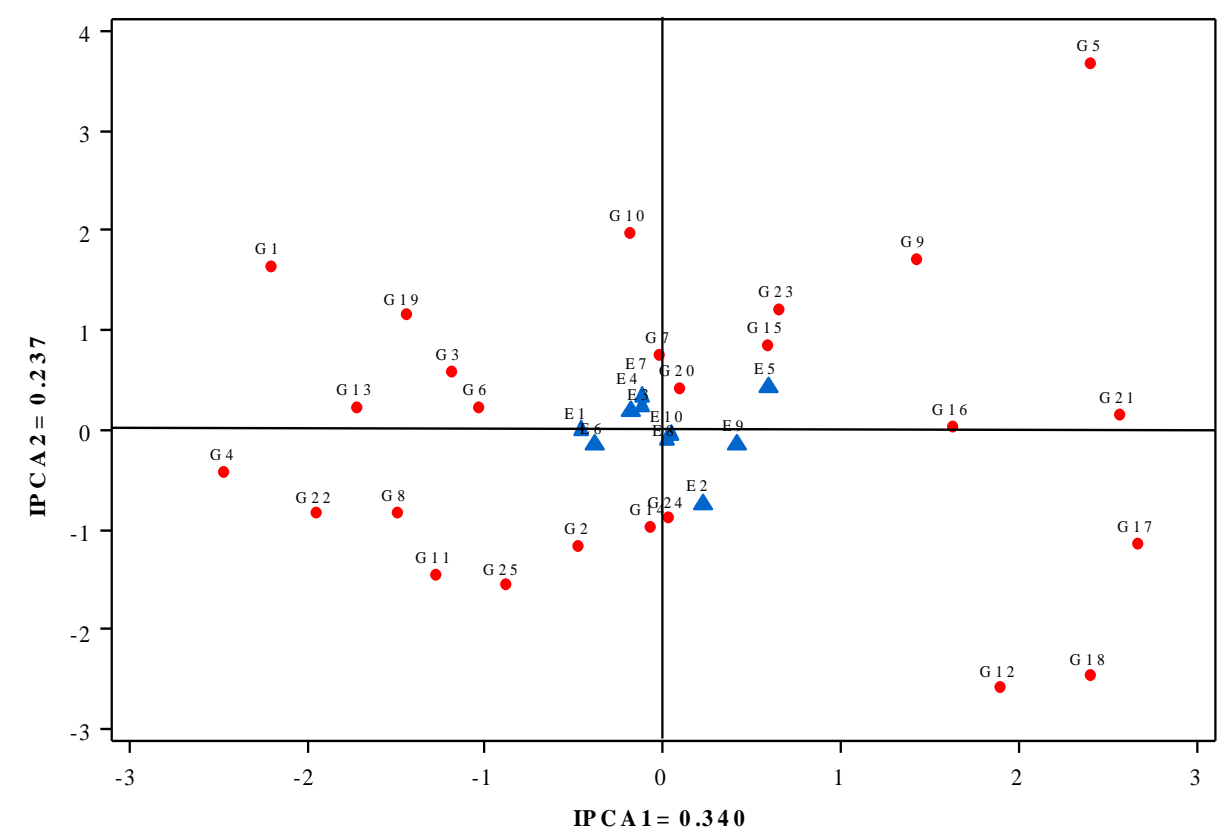

Figure 2- The bi-plot of the first two principal axis scores of potato breeding lines, standard cultivars, and environments

This study calculated other parameters of the AMMI method including $\mathrm{SIPC}_{1}, \mathrm{FA}_{1}, \mathrm{Za}_{1}, \mathrm{Dz}_{1}, \mathrm{EV}_{1}$, and Da $\mathrm{Da}_{1}$ (type 1, using the first IPCA); $\mathrm{SIPC}_{2}, \mathrm{FA}_{2}, \mathrm{Za}_{2}, \mathrm{Dz}_{2}, \mathrm{EV}_{2}$, and $\mathrm{Da}_{2}$ (type 2, based on the first and second IPCA); $\mathrm{SIPC}_{3}, \mathrm{FA}_{3}, \mathrm{Za}_{3}, \mathrm{Dz}_{3}, \mathrm{EV}_{3}$, and $\mathrm{Da}_{3}$ (type 3, using three principal components); and $\mathrm{SIPC}_{4}, \mathrm{FA}_{4}, \mathrm{Za}_{4}, \mathrm{Dz}_{4}, \mathrm{EV}_{4}$, and $\mathrm{Da}_{4}$ (type 4, based on the four components) (Tables 6, 7, and 8). Also, MASV and ASV were calculated based on the first two and four principal components and their sum of squares, respectively (Tables 6, 7, and 8). 
Table 6- The SIPC and FA parameters of the AMMI model for tuber yields of 25 genotypes tested in 10 environments

\begin{tabular}{|c|c|c|c|c|c|c|c|c|c|c|c|c|}
\hline Genotypes & $M T Y$ & SIPC1 & SIPC2 & SIPC3 & SIPC4 & $S T D_{S I P C}$ & $F A_{l}$ & $F A_{2}$ & $F A_{3}$ & $F A_{4}$ & $S T D_{F A}$ & $M A S V$ \\
\hline G1 & 35.57 & 2.203 & 3.829 & 5.066 & 6.122 & 1.686 & 298.313 & 433.886 & 492.426 & 530.393 & 101.70 & 4.352 \\
\hline G2 & 29.30 & 0.47 & 1.652 & 1.807 & 2.449 & 0.825 & 13.601 & 85.230 & 86.145 & 100.167 & 39.06 & 2.166 \\
\hline G3 & 32.99 & 1.192 & 1.765 & 3.299 & 3.871 & 1.260 & 87.286 & 104.125 & 194.136 & 205.266 & 60.60 & 2.934 \\
\hline G4 & 29.71 & 2.462 & 2.892 & 3.201 & 3.814 & 0.569 & 372.493 & 381.965 & 385.624 & 398.401 & 10.72 & 3.133 \\
\hline G5 & 41.21 & 2.407 & 6.081 & 6.335 & 7.589 & 2.230 & 356.071 & 1048.471 & 1050.932 & 1104.501 & 356.89 & 6.914 \\
\hline G6 & 32.73 & 1.035 & 1.243 & 1.249 & 1.43 & 0.161 & 65.827 & 68.040 & 68.042 & 69.155 & 1.40 & 1.301 \\
\hline G7 & 30.01 & 0.016 & 0.768 & 1.399 & 2.017 & 0.857 & 0.015 & 29.022 & 44.248 & 57.270 & 24.62 & 1.693 \\
\hline G8 & 35.05 & 1.49 & 2.335 & 3.108 & 4.835 & 1.425 & 136.385 & 173.019 & 195.886 & 297.424 & 69.00 & 3.085 \\
\hline G9 & 32.44 & 1.427 & 3.139 & 4.593 & 6.495 & 2.153 & 125.142 & 275.428 & 356.250 & 479.412 & 148.55 & 4.419 \\
\hline G10 & 30.39 & 0.188 & 2.158 & 2.678 & 4.154 & 1.639 & 2.176 & 201.146 & 211.473 & 285.652 & 121.28 & 3.701 \\
\hline G11 & 31.36 & 1.278 & 2.739 & 4.891 & 5.685 & 2.011 & 100.377 & 209.869 & 387.106 & 408.541 & 147.34 & 4.407 \\
\hline G12 & 31.37 & 1.897 & 4.497 & 5.87 & 8.087 & 2.591 & 221.253 & 567.939 & 640.067 & 807.411 & 246.60 & 5.767 \\
\hline G13 & 27.55 & 1.717 & 1.932 & 2.915 & 3.504 & 0.840 & 181.196 & 183.563 & 220.562 & 232.384 & 25.93 & 2.626 \\
\hline G14 & 31.58 & 0.071 & 1.052 & 2.759 & 3.494 & 1.563 & 0.306 & 49.687 & 161.172 & 179.570 & 86.65 & 3.135 \\
\hline G15 & 29.35 & 0.596 & 1.434 & 1.762 & 3.676 & 1.302 & 21.822 & 57.838 & 61.949 & 186.627 & 72.00 & 2.526 \\
\hline G16 & 29.32 & 1.631 & 1.645 & 2.758 & 3.47 & 0.900 & 163.450 & 163.461 & 210.879 & 228.127 & 33.12 & 2.670 \\
\hline G17 & 33.38 & 2.673 & 3.819 & 5.798 & 6.568 & 1.787 & 439.307 & 506.661 & 656.524 & 676.716 & 115.42 & 4.836 \\
\hline G18 & 30.84 & 2.399 & 4.884 & 5.929 & 7.335 & 2.083 & 353.755 & 670.552 & 712.351 & 779.661 & 188.97 & 5.476 \\
\hline G19 & 33.96 & 1.443 & 2.582 & 2.897 & 4.443 & 1.237 & 127.907 & 194.422 & 198.228 & 279.612 & 62.10 & 3.039 \\
\hline G20 & 30.10 & 0.094 & 0.502 & 2.308 & 2.722 & 1.302 & 0.544 & 9.092 & 133.877 & 139.719 & 76.32 & 2.833 \\
\hline G21 & 31.18 & 2.572 & 2.708 & 3.277 & 4.864 & 1.051 & 406.450 & 407.400 & 419.787 & 505.526 & 47.55 & 3.578 \\
\hline G22 & 28.61 & 1.944 & 2.796 & 4.237 & 5.311 & 1.497 & 232.361 & 269.618 & 349.071 & 388.306 & 71.45 & 3.648 \\
\hline G23 & 30.37 & 0.659 & 1.862 & 2.728 & 2.734 & 0.981 & 26.657 & 100.915 & 129.600 & 129.601 & 48.61 & 2.524 \\
\hline G24 & 31.14 & 0.031 & 0.933 & 2.943 & 4.192 & 1.889 & 0.060 & 41.830 & 196.413 & 249.486 & 119.84 & 3.602 \\
\hline G25 & 33.52 & 0.886 & 2.462 & 4.336 & 4.593 & 1.738 & 48.241 & 175.582 & 309.945 & 312.189 & 126.19 & 4.011 \\
\hline Mean yield & 31.75 & & & & & & & & & & & \\
\hline
\end{tabular}

MTY, Mean Tuber Yield $\left(\mathrm{t} \mathrm{ha}^{-1}\right)$; STD, Standard Deviation

Table 7- The Za and Dz parameters of the AMMI model for tuber yields of 25 genotypes tested in 10 environments

\begin{tabular}{|c|c|c|c|c|c|c|c|c|c|c|c|c|}
\hline Genotypes & $M T Y$ & $Z a_{1}$ & $Z a_{2}$ & $Z a_{3}$ & $\mathrm{Za4}$ & $S T D_{Z a}$ & $D z, 1$ & $D z, 2$ & $D z, 3$ & $D z 4$ & $S T D_{D z}$ & $A S V$ \\
\hline G1 & 35.57 & 0.096 & 0.149 & 0.176 & 0.195 & 0.043 & 0.281 & 0.361 & 0.413 & 0.451 & 0.073 & 3.100 \\
\hline $\mathrm{G} 2$ & 29.30 & 0.020 & 0.060 & 0.063 & 0.074 & 0.023 & 0.060 & 0.176 & 0.177 & 0.209 & 0.065 & 1.309 \\
\hline G3 & 32.99 & 0.052 & 0.071 & 0.103 & 0.114 & 0.029 & 0.152 & 0.172 & 0.302 & 0.317 & 0.086 & 1.539 \\
\hline G4 & 29.71 & 0.107 & 0.121 & 0.128 & 0.139 & 0.013 & 0.314 & 0.320 & 0.324 & 0.340 & 0.011 & 2.981 \\
\hline G5 & 41.21 & 0.104 & 0.226 & 0.231 & 0.254 & 0.067 & 0.307 & 0.598 & 0.599 & 0.637 & 0.153 & 4.671 \\
\hline G6 & 32.73 & 0.045 & 0.052 & 0.052 & 0.055 & 0.004 & 0.132 & 0.135 & 0.135 & 0.139 & 0.003 & 1.258 \\
\hline G7 & 30.01 & 0.001 & 0.026 & 0.039 & 0.050 & 0.021 & 0.002 & 0.105 & 0.146 & 0.181 & 0.077 & 0.752 \\
\hline G8 & 35.05 & 0.065 & 0.093 & 0.109 & 0.140 & 0.031 & 0.190 & 0.224 & 0.256 & 0.391 & 0.088 & 1.975 \\
\hline G9 & 32.44 & 0.062 & 0.119 & 0.150 & 0.183 & 0.052 & 0.182 & 0.300 & 0.381 & 0.502 & 0.135 & 2.420 \\
\hline G10 & 30.39 & 0.008 & 0.073 & 0.084 & 0.111 & 0.044 & 0.024 & 0.276 & 0.289 & 0.384 & 0.154 & 1.983 \\
\hline G11 & 31.36 & 0.055 & 0.104 & 0.150 & 0.164 & 0.049 & 0.163 & 0.261 & 0.435 & 0.456 & 0.141 & 2.117 \\
\hline G12 & 31.37 & 0.082 & 0.168 & 0.198 & 0.237 & 0.066 & 0.242 & 0.436 & 0.490 & 0.620 & 0.157 & 3.454 \\
\hline G13 & 27.55 & 0.074 & 0.082 & 0.103 & 0.113 & 0.018 & 0.219 & 0.221 & 0.272 & 0.290 & 0.036 & 2.069 \\
\hline G14 & 31.58 & 0.003 & 0.036 & 0.072 & 0.085 & 0.037 & 0.009 & 0.137 & 0.308 & 0.333 & 0.153 & 0.985 \\
\hline G15 & 29.35 & 0.026 & 0.054 & 0.061 & 0.095 & 0.028 & 0.076 & 0.140 & 0.149 & 0.360 & 0.124 & 1.101 \\
\hline G16 & 29.32 & 0.071 & 0.071 & 0.095 & 0.108 & 0.018 & 0.208 & 0.208 & 0.275 & 0.301 & 0.047 & 1.954 \\
\hline G17 & 33.38 & 0.116 & 0.154 & 0.196 & 0.210 & 0.043 & 0.341 & 0.377 & 0.494 & 0.512 & 0.085 & 3.402 \\
\hline G18 & 30.84 & 0.104 & 0.186 & 0.209 & 0.234 & 0.056 & 0.306 & 0.463 & 0.493 & 0.548 & 0.104 & 3.800 \\
\hline G19 & 33.96 & 0.063 & 0.100 & 0.107 & 0.135 & 0.030 & 0.184 & 0.243 & 0.248 & 0.363 & 0.075 & 2.071 \\
\hline G20 & 30.10 & 0.004 & 0.018 & 0.056 & 0.064 & 0.029 & 0.012 & 0.058 & 0.298 & 0.306 & 0.155 & 0.423 \\
\hline G21 & 31.18 & 0.112 & 0.116 & 0.128 & 0.156 & 0.020 & 0.328 & 0.329 & 0.341 & 0.436 & 0.052 & 3.085 \\
\hline $\mathrm{G} 22$ & 28.61 & 0.084 & 0.113 & 0.143 & 0.162 & 0.034 & 0.248 & 0.275 & 0.360 & 0.405 & 0.073 & 2.480 \\
\hline G23 & 30.37 & 0.029 & 0.068 & 0.087 & 0.087 & 0.028 & 0.084 & 0.188 & 0.234 & 0.234 & 0.071 & 1.439 \\
\hline G24 & 31.14 & 0.001 & 0.031 & 0.074 & 0.096 & 0.043 & 0.004 & 0.126 & 0.349 & 0.409 & 0.190 & 0.903 \\
\hline G25 & 33.52 & 0.038 & 0.091 & 0.131 & 0.135 & 0.045 & 0.113 & 0.247 & 0.391 & 0.394 & 0.134 & 1.900 \\
\hline
\end{tabular}


Table 8- The EV and Da parameters of the AMMI model for tuber yields of 25 genotypes tested in 10 environments

\begin{tabular}{|c|c|c|c|c|c|c|c|c|c|c|c|c|}
\hline Genotypes & $M T Y$ & $E V_{1}$ & $E V_{2}$ & $E V_{3}$ & $E V_{4}$ & $S T D_{E V}$ & $D a_{1}$ & $D a_{2}$ & $D a_{3}$ & $\mathrm{Da}_{4}$ & $S T D_{D a}$ & $A S V$ \\
\hline G1 & 35.57 & 0.079 & 0.065 & 0.057 & 0.051 & 0.012 & 17.272 & 20.830 & 22.191 & 23.030 & 2.540 & 3.100 \\
\hline $\mathrm{G} 2$ & 29.30 & 0.004 & 0.015 & 0.010 & 0.011 & 0.005 & 3.688 & 9.232 & 9.281 & 10.008 & 2.931 & 1.309 \\
\hline G3 & 32.99 & 0.023 & 0.015 & 0.030 & 0.025 & 0.006 & 9.343 & 10.204 & 13.933 & 14.327 & 2.545 & 1.539 \\
\hline G4 & 29.71 & 0.099 & 0.051 & 0.035 & 0.029 & 0.032 & 19.300 & 19.544 & 19.637 & 19.960 & 0.273 & 2.981 \\
\hline G5 & 41.21 & 0.094 & 0.179 & 0.120 & 0.101 & 0.038 & 18.870 & 32.380 & 32.418 & 33.234 & 6.915 & 4.671 \\
\hline G6 & 32.73 & 0.017 & 0.009 & 0.006 & 0.005 & 0.006 & 8.113 & 8.249 & 8.249 & 8.316 & 0.085 & 1.258 \\
\hline G7 & 30.01 & 0.000 & 0.006 & 0.007 & 0.008 & 0.004 & 0.123 & 5.387 & 6.652 & 7.568 & 3.329 & 0.752 \\
\hline G8 & 35.05 & 0.036 & 0.025 & 0.022 & 0.038 & 0.008 & 11.678 & 13.154 & 13.996 & 17.246 & 2.355 & 1.975 \\
\hline G9 & 32.44 & 0.033 & 0.045 & 0.048 & 0.063 & 0.012 & 11.187 & 16.596 & 18.875 & 21.895 & 4.523 & 2.420 \\
\hline G10 & 30.39 & 0.001 & 0.038 & 0.028 & 0.037 & 0.017 & 1.475 & 14.183 & 14.542 & 16.901 & 6.972 & 1.983 \\
\hline G11 & 31.36 & 0.027 & 0.034 & 0.063 & 0.052 & 0.017 & 10.019 & 14.487 & 19.675 & 20.212 & 4.805 & 2.117 \\
\hline G12 & 31.37 & 0.059 & 0.095 & 0.080 & 0.096 & 0.018 & 14.875 & 23.831 & 25.300 & 28.415 & 5.810 & 3.454 \\
\hline G13 & 27.55 & 0.048 & 0.024 & 0.025 & 0.021 & 0.012 & 13.461 & 13.549 & 14.851 & 15.244 & 0.906 & 2.069 \\
\hline G14 & 31.58 & 0.000 & 0.009 & 0.032 & 0.028 & 0.015 & 0.553 & 7.049 & 12.695 & 13.400 & 5.968 & 0.985 \\
\hline G15 & 29.35 & 0.006 & 0.010 & 0.007 & 0.032 & 0.013 & 4.671 & 7.605 & 7.871 & 13.661 & 3.763 & 1.101 \\
\hline G16 & 29.32 & 0.043 & 0.022 & 0.025 & 0.023 & 0.010 & 12.785 & 12.785 & 14.522 & 15.104 & 1.195 & 1.954 \\
\hline G17 & 33.38 & 0.116 & 0.071 & 0.081 & 0.065 & 0.023 & 20.960 & 22.509 & 25.623 & 26.014 & 2.446 & 3.402 \\
\hline G18 & 30.84 & 0.094 & 0.107 & 0.081 & 0.075 & 0.014 & 18.808 & 25.895 & 26.690 & 27.922 & 4.099 & 3.800 \\
\hline G19 & 33.96 & 0.034 & 0.030 & 0.021 & 0.033 & 0.006 & 11.310 & 13.944 & 14.079 & 16.722 & 2.210 & 2.071 \\
\hline G20 & 30.10 & 0.000 & 0.002 & 0.030 & 0.023 & 0.015 & 0.738 & 3.015 & 11.571 & 11.820 & 5.746 & 0.423 \\
\hline G21 & 31.18 & 0.108 & 0.054 & 0.039 & 0.048 & 0.031 & 20.161 & 20.184 & 20.489 & 22.484 & 1.113 & 3.085 \\
\hline $\mathrm{G} 22$ & 28.61 & 0.062 & 0.038 & 0.043 & 0.041 & 0.011 & 15.243 & 16.420 & 18.683 & 19.705 & 2.043 & 2.480 \\
\hline $\mathrm{G} 23$ & 30.37 & 0.007 & 0.018 & 0.018 & 0.014 & 0.005 & 5.163 & 10.046 & 11.384 & 11.384 & 2.956 & 1.439 \\
\hline $\mathrm{G} 24$ & 31.14 & 0.000 & 0.008 & 0.041 & 0.042 & 0.022 & 0.246 & 6.468 & 14.015 & 15.795 & 7.172 & 0.903 \\
\hline G25 & 33.52 & 0.013 & 0.031 & 0.051 & 0.039 & 0.016 & 6.946 & 13.251 & 17.605 & 17.669 & 5.057 & 1.900 \\
\hline
\end{tabular}

Based on type 1 parameters, genotypes G7, G10, G14, G20, and G24 (cv. Agria) were found to be the most stable ones due to their lowest values. According to type 2 parameters, genotypes G6, G7, G14, G15, G20, and G24 (cv. Agria) were selected as the most stable genotypes. Genotypes G2, G6, G7, G14, G15, G20, and G23 (cv. Luta) were the stable ones based on the type 3 parameters. Genotypes G2, G6, G7, G20, and G23 (cv. Luta) accounted for the lowest values based on the type 4 parameters. The standard deviation was computed for all parameters. Genotypes G2, G7, G6, and G23 (cv. 'Luta') showed the lowest standard deviation of the EV parameter. Cultivar Caesar and genotypes G4, G6, and G16 obtained the lowest value of the standard deviation of D and Za parameters. The standard deviation value of the parameter SIPC for genotypes G2, G4, G6, and G13 (cv. Caesar) and Da for genotypes G4, G6, G13 (cv. Caesar), and G21 were the lowest. Genotypes G4, G6, G7, and G13 (cv. Caesar) acquired the lowest value of standard deviation in terms of the FA criterion.

Since genotypes G6, G7, G14, G15, G20, and G24 (cv. Agria) had the lowest values of ASV parameter, they were considered as the stable genotypes. On the other hand, genotypes G5, G12, G17, and G18 had the highest values of this parameter. Thus, they were selected as the unstable ones (Table 7 and 8). Based on the MASV parameter, genotypes G6, and G7 were selected as the stable genotypes. However, genotypes G5, G10, G12, G17, and G18 were found to be unstable.

GEI was found to be significant in the present study and was six times greater than genotype main effect. This reflects its complexity and high effect on tuber yield in various environments. The large magnitude of GEI causes more dissimilarity in the genetic systems that control the physiological processes that are conferring yield stability in different environments (Karimizadeh et al. 2016, 2019).

Additionally, the significance of GEI is indicative of the genotypes' evaluation in several environments to identify the general and specific adaptation. Thus, considering the significance of GEI, the AMMI method and its parameters were utilized to select the stable genotype. GEI stability is in biological or agricultural forms (Tollenaar \& Lee 2002). Breeders tend to use agricultural and dynamic concept of stability instead of its static concept. According to this concept, there is a predictable response in relation to the environmental factors, and the yield of genotypes is likely to be improved through enhancing the environmental conditions. The genotype yield matches the estimated or predicted levels in all environments (Tollenaar \& Lee 2002). Sabbaghniya et al. (2008, 2013) expressed that the AMMI method and its parameters were useful for investigating static stability. Zali et al. (2012) investigated the AMMI parameters and classified them into two groups. While the first group included EV, MASV, DZ, SIPC, and FA, the second group consisted of ZA, ASV, and Da. They stated that both of the groups were closely associated with the mean yield. Karimizadeh et al. (2016) stated that ASV features agricultural concepts of stability.

According to the parameters of type I ( $\mathrm{SIPC}_{1}, \mathrm{FA}_{1}, \mathrm{Za}_{1}, \mathrm{Dz}_{1}, \mathrm{EV}_{1}$, and $\left.\mathrm{Da}_{1}\right)$, genotypes G7, G10, G14, G20, and G24 were stable although their yields were below the grand mean (Table 9). Hence, they cannot be considered as the ideal breeding lines. These breeding lines possess the Type I stability, which is equivalent to the biological stability (Lin et al. 1986). The tuber yields of genotypes G14 and G24 were nearly equal to the grand mean. Thus, these breeding lines can be used in breeding programs where the qualitative characteristics are of interest. 
Table 9- The two-way table of the environment and genotype means

\begin{tabular}{|c|c|c|c|c|c|c|c|c|c|c|c|}
\hline Genotypes & $\begin{array}{c}\text { Ardabil } \\
(2016) \\
\text { E1 }\end{array}$ & $\begin{array}{c}\text { Hamedan } \\
(2016) \\
\text { E2 }\end{array}$ & $\begin{array}{c}\text { Karaj } \\
(2016) \\
\text { E3 }\end{array}$ & $\begin{array}{c}\text { Isfahan } \\
(2016) \\
\text { E4 }\end{array}$ & $\begin{array}{c}\text { Razavi } \\
\text { Khorasan } \\
(2016) \\
\text { E5 }\end{array}$ & $\begin{array}{c}\text { Ardabil } \\
(2017) \\
\text { E6 }\end{array}$ & $\begin{array}{c}\text { Hamedan } \\
(2017) \\
\text { E7 }\end{array}$ & $\begin{array}{c}\text { Karaj } \\
(2017) \\
\text { E8 }\end{array}$ & $\begin{array}{c}\text { Isfahan } \\
(2017) \\
\text { E9 }\end{array}$ & $\begin{array}{c}\text { Razavi } \\
\text { Khorasan } \\
(2017) \\
\text { E10 }\end{array}$ & $\begin{array}{c}\text { Genotype } \\
\text { mean }\end{array}$ \\
\hline G1 & 54.273 & 49.443 & 20.373 & 34.853 & 18.957 & 42.180 & 30.587 & 30.217 & 42.700 & 32.067 & 35.565 \\
\hline $\mathrm{G} 2$ & 43.323 & 31.847 & 19.957 & 23.593 & 33.557 & 25.893 & 24.567 & 26.770 & 29.217 & 34.310 & 29.303 \\
\hline G3 & 36.193 & 48.187 & 31.613 & 23.593 & 27.297 & 42.513 & 30.347 & 29.130 & 28.520 & 32.533 & 32.993 \\
\hline G4 & 46.540 & 36.440 & 22.503 & 29.490 & 20.800 & 33.457 & 30.910 & 27.853 & 24.147 & 24.933 & 29.707 \\
\hline G5 & 44.067 & 80.960 & 24.167 & 27.883 & 43.257 & 31.633 & 28.653 & 39.750 & 53.830 & 37.863 & 41.206 \\
\hline G6 & 39.930 & 44.390 & 27.117 & 28.957 & 27.180 & 37.430 & 30.790 & 31.130 & 35.047 & 25.277 & 32.725 \\
\hline G7 & 42.043 & 45.053 & 17.693 & 18.767 & 30.910 & 29.430 & 23.877 & 29.350 & 34.120 & 28.897 & 30.014 \\
\hline G8 & 52.570 & 41.210 & 20.497 & 39.143 & 33.027 & 28.487 & 34.543 & 37.463 & 27.957 & 35.617 & 35.051 \\
\hline G9 & 33.290 & 58.830 & 21.290 & 19.570 & 36.180 & 25.230 & 23.413 & 32.823 & 32.563 & 41.200 & 32.439 \\
\hline G10 & 40.507 & 46.863 & 19.187 & 19.300 & 22.373 & 35.060 & 18.452 & 28.670 & 44.650 & 28.833 & 30.390 \\
\hline G11 & 52.443 & 33.923 & 19.317 & 26.813 & 36.543 & 33.983 & 32.653 & 24.180 & 31.440 & 22.350 & 31.365 \\
\hline G12 & 29.223 & 38.780 & 29.383 & 25.203 & 51.907 & 18.770 & 33.457 & 25.797 & 27.660 & 33.533 & 31.371 \\
\hline Caesar & 42.250 & 34.670 & 25.297 & 18.763 & 17.667 & 30.917 & 21.300 & 23.463 & 29.050 & 32.166 & 27.554 \\
\hline G14 & 47.343 & 33.040 & 19.000 & 22.520 & 34.537 & 27.023 & 30.233 & 32.870 & 41.903 & 27.333 & 31.580 \\
\hline G15 & 34.470 & 40.987 & 17.567 & 22.520 & 23.783 & 24.873 & 23.653 & 30.130 & 46.573 & 28.917 & 29.347 \\
\hline G16 & 30.090 & 41.560 & 19.740 & 21.447 & 34.073 & 21.340 & 22.350 & 20.070 & 41.837 & 40.660 & 29.317 \\
\hline G17 & 39.247 & 41.340 & 16.830 & 25.470 & 55.800 & 23.877 & 23.990 & 32.533 & 45.747 & 28.967 & 33.380 \\
\hline G18 & 27.510 & 31.890 & 20.000 & 27.347 & 46.803 & 21.550 & 36.680 & 22.960 & 49.123 & 24.500 & 30.836 \\
\hline G19 & 50.857 & 55.210 & 22.950 & 32.707 & 25.407 & 30.170 & 33.100 & 29.997 & 30.540 & 28.700 & 33.964 \\
\hline G20 & 38.413 & 42.930 & 10.973 & 20.373 & 29.667 & 31.743 & 34.793 & 28.260 & 39.717 & 24.100 & 30.097 \\
\hline G21 & 25.517 & 44.480 & 23.997 & 22.520 & 36.130 & 18.936 & 25.567 & 33.460 & 51.040 & 30.100 & 31.175 \\
\hline Satina & 36.947 & 27.895 & 22.667 & 24.667 & 16.820 & 31.607 & 30.790 & 26.500 & 27.920 & 40.267 & 28.608 \\
\hline Luta & 35.080 & 48.540 & 21.333 & 23.325 & 26.913 & 22.323 & 21.653 & 32.153 & 37.860 & 34.500 & 30.368 \\
\hline Agria & 36.043 & 38.233 & 33.133 & 26.770 & 26.667 & 21.337 & 31.123 & 21.930 & 39.750 & 36.383 & 31.137 \\
\hline Savalan & 43.690 & 39.517 & 45.530 & 30.543 & 29.723 & 23.903 & 33.440 & 28.743 & 35.010 & 25.100 & 33.520 \\
\hline $\begin{array}{l}\text { Env. } \\
\text { mean }\end{array}$ & 40.074 & 43.049 & 22.885 & 25.445 & 31.439 & 28.547 & 28.437 & 29.048 & 37.117 & 31.164 & 31.720 \\
\hline
\end{tabular}

According to the bi-plot, genotypes G6, G7, G10, G13 (cv. Caesar), G14, G16, G20, G21, and G24 (cv. Agria) had general adaptation in the entire studied regions. Among the all stable genotypes in the study, genotype G6 produced higher yield than average yield of all genotypes tested. In addition, G14 and G24 (cv. Agria) had tuber yield near to mean tuber yield of all genotypes. The availability of cultivars that are highly adaptive to a vast range of regions is one of the important goals of the breeding programs (Mohebodini et al. 2006). Hassanpanah et al. (2018) investigated 11 genotypes in five regions and selected genotypes 397031-16, 397045-13, and 397009-8 for their yield stability and dry matter as well as the other qualitative and quantitative traits. In another study using multivariate methods and qualitative characteristics, Hassanpanah et al. (2016) selected clones 1 and 2 as the stable clones with high tuber yield and for uses as chips, French fries, and roasting.

\section{Conclusions}

Yield-stable G6 performed high tuber yield with 32.73 t/ha, and the other two yield-stable genotypes G14 and G24 (cv. Agria) produced moderate tuber yield with 31.58 t/ha and 31.14 t/ha, respectively. In conclusion, potato breeding lines G6 and G14 could be considered as candidate for registration in Iran. In addition, Agria might be proposed as a suitable variety for regions such as Ardebil, Hamadan, Razavi Khorasan, Isfahan, and Karaj.

\section{References}

Annicchiarico P (1997). Joint regression vs AMMI analysis of genotype $\times$ environment interactions for cereals in Italy. Euphytica 94: 53-62 Byarugaba A A, Benon M, Tibanyedera D \& Barekye A (2018). Genotype by environment interaction (GxE) as a measure of yield stability of Dutch potato varieties in Uganda. African Journal of Agricultural Research 13(17): 890-896 https://doi.org/10.5897/ajar2018.13061 
Crossa J, Gauch H G \& Zobel R W (1990). Additive main effects and multiplicative interaction analysis of two international maize cultivar trials. Crop Science 30: 493-500 https://doi.org/10.2135/cropsci1990.0011183x003000030003x

Crossa J, Fox P N, Pfeiffer W H, Rajaram S \& Gauch H G (1991). AMMI adjustment for statistical analysis of an international wheat yield trial. Theoretical and Applied Genetics 81: 27-37 https://doi.org/10.1007/bf00226108

Devaux A, Kromann P \& Oriza O (2014). Potatoes for sustainable global food security. Potato Research 57: 185-199 https://doi.org/10.1007/s11540-014-9265-1

Fufa M (2013). AMMI analysis of tuber yield of potato genotypes grown in bale, southeastern Ethiopia. Advances in Crop Science and Technology 2: 1-3 https://doi.org/10.4172/2329-8863.1000120

Gauch H G (1988). Model selection and validation for yield trials with interaction. Biometrics 44: 705-715 https://doi.org/10.2307/2531585.

Gauch H G \& Zobel R W (1988). Predictive and postdictive success of statistical analyses of yield trials. Theoretical and Applied Genetics 76: 1-10 https://doi.org/10.1007/bf00288824

Hassanabadi H, Mosapor-Gorgi A, Hasanpanah D, Ahmadvand R, Parvizi KH, Kazemi M, Hajianfar R \& Abdi H R (2013). Khavaran, a new potato cultivar with high yielding and quality. Research Achievements for Field and Horticulture Crops 2(1): 67-79

Hassanpanah D, Hassanabadi H, Hosseinzadeh A, Soheili B \& Mohammadi R (2016). Factor Analysis, AMMI Stability Value (ASV) Parameter and GGE Bi-Plot Graphical Method of Quantitative and Qualitative Traits in Potato Genotypes. Journal of Crop Ecophysiology 10(3): 731-748

Hassanpanah D, Hassanabadi H, Parvizi K, Kazemi M, Jalali A H, Mobser S, Kahbazi M, Hasani M, Mohammadi R \& Khashmi M R (2018). Evaluation of quantitative and qualitative traits and stability of commercial cultivars and promising clonese of potato. Seed and Plant Improvment Journal 3: 455-474

Kadhem F A \& Baktash F Y (2016). Analysis of adaptability and yield stability of promising lines of bread wheat (Triticum aestavum L.). Iraqi Journal of Agricultural Science 47: 35-43

Karimizadeh R, Mohammadi M, Sabaghnia N \& Shefazadeh M K (2012). Using Huehn's Nonparametric Stability Statistics to Investigate Genotype $\times$ Environment Interaction. Notulae Botanicae Horti Agrobotanici 40: 195-200 https://doi.org/10.15835/nbha4017593

Karimizadeh R, Asghari A, CHinipardaz R, Sofalian O \& Ghaffari A (2016). Determining yield stability and model selection by ammi method in rain-fed durum wheat genotypes. Turkish Journal of Field Crops 21(2): 174-183 https://doi.org/10.17557/tjfc.17390

Karimizadeh R, Asghari A, CHinipardaz R, Sofalian O, Ghaffari A, Shabazi K, Hosseinpour T, Ghojog H \& Armion M (2019). Use of principal coordinate analysis for measuring GE interactions in rain-fed durum wheat genotypes. Journal of Agricultural Science 25: $38-46$ https://doi.org/10.15832/ankutbd.538993

Khomari A, Mostafavi KH \& Mohammadi A (2016). Stability study of yield in sunflower (Helianthus annuus L.) cultivars using AMMI method. Journal of Crop Breeding 9(23): 117-124

Lin C S, Binns M R \& Lefkoveitch L P (1986). Stability analysis: Where do we stand? Crop Science 26: 894-900

Mohebodini M, Dehghani H \& Sabaghpour S H (2006). Stability of performance in lentil (Lens culinaris Medik.) genotypes in Iran. Euphytica 149: 343-352 https://doi.org/10.1007/s10681-006-9086-7

Omrani S, Naji A M \& Esmaeil Zadeh Moghadam M (2018). Evaluation of yield stability of bread wheat (Triticum aestivum L.) genotypes using additive main effects and multiplicative Interaction (AMMI). Journal of Crop Breeding 10: 73-80 https://doi.org/10.29252/jcb.10.25.73

Pourdad S S \& Jamshid Moghaddam M (2013). Study on genotypexenvironment interaction through GGE Biplot for seed yield in spring rapeseed (Brassica Napus L.) in rain-fed condition. Journal of Crop Breeding 5(12): 1-14

Purchase J L (1997). Parametric analysis to describe G $\times$ E interaction and yield stability in winter wheat. PhD Thesis, Department of Agronomy, Faculty of Agriculture, University of the Orange Free State (Published), Bloemfontein, South Africa

Raju B M K (2002). A study on AMMI model and its biplots. Journal of the Indian Society of Agricultural Statistics 55: 297-322

Sabaghnia N, Sabaghpour S H \& Dehghani H (2008). The use of an AMMI model and its parameters to analyse yield stability in multienvironment trials. Indian Agricultural Science 146: 571-581 https://doi.org/10.1017/s0021859608007831

Sabaghnia, N, Mohammadi M \& Karimizadeh R (2013). Parameters of AMMI model for yield stability analysis in durum wheat. Agriculturae conspectus Scientificus 78: 119-124

Safavi S M \& Bahraminejad S (2017). The evaluation of genotype $\times$ environment interactions for grain yield of oat genotypes using AMMI model. Journal of Crop Breeding 9: 125-132 https://doi.org/10.29252/jcb.9.22.125

Shafii B \& Price W J (1998). Analysis of genotype-by-environment interaction using the additive main effecta and multiplicative interaction model and stability estimates. Journal of Agricultural Biological and Environmental Statistics 3: 335-345 https://doi.org/10.2307/1400587

Sneller C H, Kilgore Norquest L \& Dombek D (1997). Repeatability of yield stability statistics in soybean. Crop Science 37: 383-390 https://doi.org/10.2135/cropsci1997.0011183x003700020013x

Tarakanovas P \& Ruzgas V (2006). Additive main effect and multiplication analysis of grain yield of wheat varieties in lithunia. Agricultural Research 4: 91-94

Tollenaar M \& Lee E A (2002). Yield potential, yield stability and stress tolerance in maize. Field Crop Research 75: 161-169 https://doi.org/10.1016/s0378-4290(02)00024-2

Worku A, Mulugeta G, Berhun B, Abebe T, Giorgis G W, Chindie A \& Kebede G (2018). Performance and yield stability analysis of potato genotypes in ethiopia. Advances in Crop Science and Technology 6(1): 1-8. https://doi.org/10.4172/2329-8863.1000336

Zali H, Farshadfar E, Sabaghpour S H \& Karimizadeh R (2012). Evaluation of genotype $\times$ environment interaction in chickpea using measures of stability from AMMI model. Annals of Biological Research 3(7): 3126-3136

Zhang Z, Lu C \& Xiang Z H (1998). Stability analysis for varieties by AMMI model. Acta Agronomica Sinica 24: 304-309

Zobel R W (1994). Stress resistance and root systems. In: 1-4 Aug. 1993. Of the Workshop on Adaptation of Plants to Soil Stresses, INTSORMIL Publ. 94-2. Inst., Univ Nebraska, Lincoln pp. 80-99

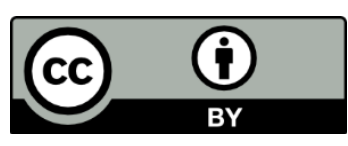

(C) 2021 by the authors. Licensee Ankara University, Faculty of Agriculture, Ankara, Turkey. This article is an open access article distributed under the terms and conditions of the Creative Commons Attribution (CC BY) license (http://creativecommons.org/licenses/by/4.0/). 